Received: 4 September 2017

Accepted: 23 November 2017

Published online: 06 December 2017

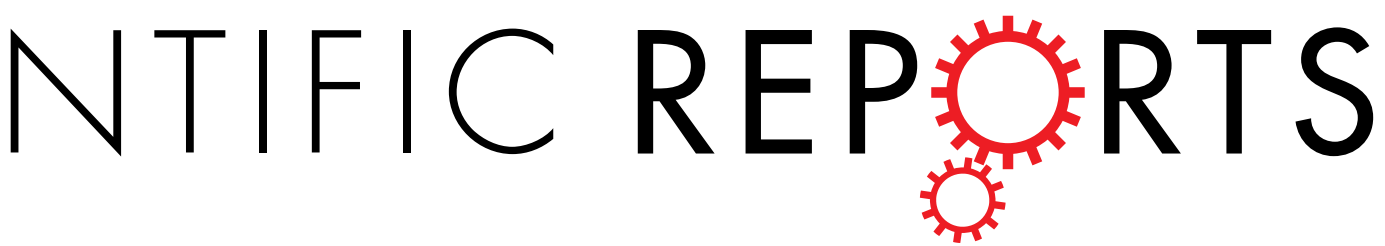

\title{
Preparation of Permanent Magnetic Resin Crosslinking by Diallyl Itaconate and Its Adsorptive and Anti-fouling Behaviors for Humic Acid Removal
}

\author{
Oimeng Li, Ji Wu, Ming Hua, Guang Zhang, Wentao Li, Chendong Shuang \& Aimin Li
}

In this research, a series of permanent magnetic anion exchange resins (MAERs) were prepared by polymerizing glycidyl methacrylate monomer and crosslinking diallyl itaconate (DAI) and divinylbenzene. The properties and performances of these novel MAERs were systematically characterized and evaluated for humic acid (HA) adsorption by batch experiments. With the increase of DAl content from 0 to $15 \%$, the moisture of MAERs was elevated from $50.23 \%$ to $68.53 \%$, along with the adsorption capacity increasing from 2.57 to $3.14 \mathrm{mmol} \mathrm{g}^{-1}$. As the concentrations of co-existing cation $\left(\mathrm{Ca}^{2+}\right.$ and $\left.\mathrm{Mg}^{2+}\right)$ increased, the adsorption amounts of HA dropped drastically at first and increased a little at high cation concentrations. Although ion exchange was the primary mechanism for HA adsorption, other physical interactions and electrostatic attraction between HA molecules and newly formed oxonium group also played significant roles for HA adsorption. The MAERs could be efficiently regenerated by a mixture of $\mathrm{NaCl} / \mathrm{NaOH}$ solution $(10 \% / 1 \%)$, and notably, the MAER-3 with the highest DAl content displayed unapparent loss of adsorption capacity during twenty-one successive adsorption-desorption cycles. These results suggested a novel resin adsorbent for its excellent performances on adsorption, regeneration, and sedimentation in water treatment for natural organic matter removal.

Natural organic matter (NOM), commonly present in various water systems, can cause serious environmental problems, such as undesirable color and formation of disinfection byproducts during the chlorination disinfection, thus are potentially harmful to human health ${ }^{1,2}$. Therefore, it is of crucial importance to reduce NOM concentration in drinking water and other processing water streams.

Many groups have researched on numerous methods for NOM removal, including biological degradation ${ }^{3}$, enhanced coagulation ${ }^{4}$, oxidation ${ }^{5}$, adsorption ${ }^{6}$, membrane filtration $^{7}$, and ion exchange ${ }^{8,9}$. Among them, ion-exchange has attracted extensive attention to remove various pollutants from wastewater for its high regeneration efficiency and simple operation ${ }^{10,11}$. MIEX resin, developed by Orica Co. Ltd, is currently the most widely used magnetic resin for NOM removal ${ }^{12}$. Multiple water treatment projects based on MIEX resin for water purification have been established worldwide, which are mainly owing to its recognized advantages: macroporous structure, high exchange capacity and improved kinetics ${ }^{13-15}$. Furthermore, due to its high density and excellent settling property, MIEX resin could be applied in the form of fluidized bed reactor in a continuous process with partial resin regeneration, which greatly improves the treatment flux ${ }^{14}$.

Although magnetic resins have been found appealing in a large number of industrial-scale water treatment applications and installed new plants continuously, the magnetic resins still attract less attention than they deserve. There is a strong need for developing more efficient and commercially available magnetic resins on the aspects of adsorption, desorption and settlement. The primary concern is how the magnetic iron oxide $\left(\gamma-\mathrm{Fe}_{2} \mathrm{O}_{3}\right)$ is embedded in the resin matrix ${ }^{15}$. The resulting agglomeration and rapid settling of dense magnetic microbeads

State Key Laboratory of Pollution Control and Resources Reuse, School of the Environment, Nanjing University, Nanjing, 210023, P. R. China. Correspondence and requests for materials should be addressed to C.S. (email: shuangchendong@nju.edu.cn) or A.L. (email: liaimin@nju.edu.cn) 
in solution are the sticking points for magnetic resin adsorption processes ${ }^{15,16}$. On the other hand, it is surprising that fewer research papers focus on the resin fouling by NOM. Although the decline in NOM removal can be ignored in some cases during several regeneration cycles, resin adsorption performance can be significantly influenced because hundreds to thousands of adsorption-regeneration cycles occur in real applications ${ }^{17-19}$. Generally, the optimization of resin adsorbents for improving their anti-fouling performance depends on improving their polymer matrix and porosity ${ }^{18,20,21}$. Polyacrylic matrix and macroporous structure are reported to be favorable for resin regeneration because of their more hydrophilic and open structure ${ }^{15}$. Shuang et al. ${ }^{14}$ recently developed a novel magnetic anion exchange resin called NDMP, which incorporated with different amount of nanoscale $\mathrm{Fe}_{3} \mathrm{O}_{4}$ and exhibited significantly improved adsorption and reusability performances due to its much more enhanced resin hydrophilicity. The use of polar and hydrophilic crosslinker can also improve the hydrophilicity and change the structure of the resin matrix. However, few studies are reported in this field.

Given that humic substances are flexible and contain plenty of carboxylic, phenolic, and carbonyl groups, they can be easily adsorbed by anion exchange resins and, on the other hand, cause severe resin fouling problem ${ }^{14,20}$. The mutual interactions between resin and fouling pollutants were found to be diversiform in previous studies. For example, Fu et al. ${ }^{22}$ concluded that NOM was removed via ion exchange, yet others have shown evidence of both ion exchange and adsorption ${ }^{23}$. Therefore, the influences of resin properties and adsorption mechanisms should be further studied.

In this work, a series of novel permanent-magnetic anion exchange resins (MAERs) with the different amount of crosslinker DAI in feed compositions were prepared. A commercial Alfa humic acid (HA) was chosen as the model adsorbate. The purposes of this work were to (1) systematically study the adsorption behaviors of HA by MAERs under different conditions; (2) investigate the regeneration and reusability performance of MAERs on HA removal; and (3) elucidate the adsorption mechanisms between HA and MAERs.

\section{Experimental Section}

Materials. Glycidyl methacrylate (GMA, >99\%), divinylbenzene (DVB, 63.3\%), benzoyl peroxide (BPO), trimethylamine hydrochloride, cyclohexanol and polyvinyl alcohol (PVA, GH20) were all industrial products and supplied by J\&K Chemical Co. Ltd., China. Commercial $\gamma-\mathrm{Fe}_{2} \mathrm{O}_{3}$ was obtained from Tangyin Zhongke magnetoelectric Co., Ltd. Tetraethoxysilane (TEOS) and dimethyldiethoxylsilane (DMDES) were purchased from Nanjing Capture Chemical Co., Ltd. All these reagents were used as supplied without further purification. Diallyl itaconate (DAI) was obtained by the esterification reaction of propanol and itaconic acid. Detailed preparation procedures were described in Text S1, supplementary information.

Synthesis of MAERs. As the $\gamma-\mathrm{Fe}_{2} \mathrm{O}_{3}$ particles used in this work were commercial micrometer-scale products and had been calcined for surface passivation, the big spatial hindrance and poor surface active groups made the $\gamma-\mathrm{Fe}_{2} \mathrm{O}_{3}$ particles much more difficult for surface modification. However, by modification with silane coupling agents (TEOS + DMDES) for two times, the $\gamma-\mathrm{Fe}_{2} \mathrm{O}_{3}$ could be successfully encapsulated into the resin matrix, which was similar to Wang's method ${ }^{24}$.

Three magnetic resins noted as MAER-1 to MAER-3 were synthesized through suspension polymerization and amination reaction. For polyacrylic resins, the DAI could readily polymerize with the monomers due to their high reactivity ratio and similar compatibility $(\log D 1.70, \log P 1.704 \pm 0.439)$. With the different amount of crosslinker DAI and DVB in feed, the resins with different hydrophilicity and polarity could be prepared. Detailed synthetic steps and compositions of oil phase for each resin were illustrated in Text S2 and Table S1.

Characterization of MAERs. The functional groups of resins were identified by FTIR spectroscopy (Nexus870, Nicolet). The morphologies of microbeads were characterized via scanning electron microscopy (SEM, S-3400, Hitachi). The specific surface area and pore distribution of the resins were measured by $\mathrm{N}_{2}$ adsorption-desorption experiments at $77 \mathrm{~K}$ (ASAP, Micromeritics, USA) based on the standard Brunauer-EmmettTeller (BET) method. The size distributions of magnetic precursor resins were determined by a laser diffraction particle size analyzer (Mastersizer 3000, England). The resins before and after the adsorption of HA were characterized with X-ray Photoelectron Spectroscopy (XPS, PHI 5000 VersaProbe, UlVAC-PHI Japan). All XPS spectra were calibrated against $\mathrm{C} 1 \mathrm{~s}$ bands at $284.6 \mathrm{eV}$.

Batch adsorption. Batch adsorption experiments were performed to investigate the HA adsorption behaviors of MAERs. For adsorption kinetics, $0.500 \mathrm{~g}$ of dried resin with $500 \mathrm{~mL}$ HA solution of known concentration was stirred in a $1000 \mathrm{~mL}$ conical flask at $293 \mathrm{~K}$. Water samples were withdrawn at different time intervals, and determined by a total organic carbon analyzer (OIA1088, USA).

The adsorption isotherms were performed at the temperatures of 278, 293, and $308 \mathrm{~K} .0 .100 \mathrm{~g}$ of MAERs and $100 \mathrm{~mL} H A$ solution of known concentrations were shaken for $48 \mathrm{~h}$ to attain equilibrium. Afterwards, the residual HA concentrations were determined.

The amount of adsorbed HA $Q_{t}\left(\mathrm{mg} \mathrm{g}^{-1}\right)$ was estimated as:

$$
Q_{t}=V\left(C_{0}-C_{t}\right) / W
$$

where, $C_{0}$ and $C_{t}\left(\mathrm{mg} \mathrm{L}^{-1}\right)$ are concentrations of adsorbate at the beginning and time $t$, respectively. $V(L)$ is the solution volume. $W(\mathrm{~g})$ is the weight of dried resin. The variables $Q_{t}$ and $C_{t}$ can be replaced by $Q_{e}$ and $C_{e}$ at the equilibrium state, respectively.

For the $\mathrm{pH}$-effect experiments, the initial $\mathrm{pH}$ was adjusted in the $\mathrm{pH}$ range of 3.0 to $11.0 \mathrm{using} 1.0 \mathrm{~N} \mathrm{HCl}$ or $\mathrm{NaOH}$ solution. Adsorption experiments were performed by shaking a series of conical flasks containing $0.100 \mathrm{~g}$ resin and $100 \mathrm{~mL} \mathrm{HA}$ solutions $\left(50 \mathrm{mg} \mathrm{L}^{-1}\right)$ at different $\mathrm{pH}$ values and $293 \mathrm{~K}$ for $48 \mathrm{~h}$. At each $\mathrm{pH}$ value, the adsorption experiments were repeated for three times to guarantee the replicability of results. To determine the 


\begin{tabular}{|c|c|c|c|c|c|c|c|c|}
\hline Resin & $\begin{array}{l}\text { Specific surface } \\
\text { area }\left(\mathrm{m}^{2} / \mathrm{g}\right)\end{array}$ & $\begin{array}{l}\text { External surface } \\
\text { area }\left(\mathrm{m}^{2} / \mathrm{g}\right)\end{array}$ & $\begin{array}{l}\text { Pore volume } \\
\left(\mathrm{mm}^{3} / \mathrm{g}\right)\end{array}$ & $\begin{array}{l}\text { Average pore } \\
\text { diameter }(\mathbf{n m})\end{array}$ & $\begin{array}{l}\text { Water } \\
\text { content (\%) }\end{array}$ & $\mathrm{N}(\%)$ & $\mathrm{AEC}^{1}(\mathrm{mmol} / \mathrm{g})$ & Sphericity ${ }^{2}(\%)$ \\
\hline MAER-1 & 1.109 & 0.768 & 7.311 & 26.367 & 50.23 & 2.77 & 2.57 & 72.23 \\
\hline MAER-2 & 1.396 & 0.739 & 6.527 & 18.704 & 62.14 & 3.05 & 2.93 & 80.27 \\
\hline MAER-3 & 1.785 & 1.490 & 7.518 & 16.845 & 68.53 & 3.45 & 3.14 & 86.05 \\
\hline
\end{tabular}

Table 1. Physicochemical properties of MAERs. ${ }^{1}$ Anion exchange capacity. ${ }^{2}$ Sphericity after osmotic-attrition (\%) was determined with the precursor resins.

effects of alkali-earth metal ions on HA adsorption, the HA solutions $\left(50 \mathrm{mg} \mathrm{L}^{-1}\right)$ with different concentrations of $\mathrm{Ca}^{2+}$ and $\mathrm{Mg}^{2+}$ were shaken with $0.100 \mathrm{~g}$ MAERs to investigate their effects on HA adsorption.

Desorption and reusability. The desorption and regeneration behaviors of MAERs could directly reflect their anti-fouling performance. Initially, batch adsorption experiments were conducted at $293 \mathrm{~K}$ until equilibrium. Next, the saturated resins were regenerated by $\mathrm{NaCl}$ solution $(10 \%$, w/w) or a mixture of $\mathrm{NaCl} / \mathrm{NaOH}$ solution $(10 \% / 1 \%, \mathrm{w} / \mathrm{w})$ for different time intervals. The desorption efficiency $(D E, \%)$ was calculated by the following Eq. (2):

$$
D E=100 \% \cdot V_{d} C_{d} / W q_{e}
$$

where $V_{d}(\mathrm{~L})$ is desorption agent volume, and $C_{d}\left(\mathrm{mg} \mathrm{L}^{-1}\right)$ is the final concentration of HA solution. The adsorption-desorption processes were undertaken for 21 times to verify the loss of adsorption capacity, and alternatively to know the extent of regeneration.

Continuous HA adsorption jar tests were carried out with $1.0 \mathrm{~mL}$ resin and $100 \mathrm{~mL}$ HA solution of $50 \mathrm{mg} \mathrm{L}^{-1}$ at $293 \mathrm{~K}$ and $150 \mathrm{rpm}$. After adsorption for $1 \mathrm{~h}, 1 \mathrm{~mL}$ of supernatant was withdrawn and analyzed. Then, the resins were separated by a magnet and transferred into another $100 \mathrm{~mL}$ untreated solution, which was similar as the former operation run.

\section{Results and Discussion}

Characterization. The essential physicochemical characteristics of MAERs were shown in Table 1. The BET surface area and total pore volume of MAERs were in the range of $1.1-1.8 \mathrm{~m}^{2} \mathrm{~g}^{-1}$ and $6.5-7.5 \mathrm{~mm}^{3} \mathrm{~g}^{-1}$, respectively. For the three resins, the moisture of resins increased from $50.23 \%$ to $68.53 \%$, with the DAI content in composition increasing from 0 to $15 \%$. Besides, due to the superior crosslinking capability of DAI, the resin with higher DAI content had a lower average pore size and stronger mechanical strength (indicated by the sphericity rate of precursor resins after osmotic-attrition). Unexpectedly, the anion exchange capacity (AEC) of MAERs was also affected by the DAI content, which is expressed by the content of $\mathrm{N}$ element for each resin. Therefore, the improved hydrophilicity as a function of DAI content possibly allowed the functionalizing agent (trimethylamine hydrochloride) to penetrate deeply into the resin matrix, leading to an increased AEC (tested by the content of quaternary ammonium groups).

To observe morphological characteristics of MAERs, the SEM analysis was performed and illustrated in Fig. 1. The size distributions of MAERs are shown in Supplementary Fig. S1. It is clearly seen that the beads are satisfactorily monodisperse in the range of 50-150 $\mu \mathrm{m}$, much smaller than conventional resins. Particularly, the surface of MAER-3 shows many cavities and canals, which are deemed as essential prerequisites for efficiently adsorbing high-molecular-weight pollutants like HA.

The FTIR spectra of MAERs are presented in Fig. 2a. The absorption bands at 904 and $844 \mathrm{~cm}^{-1}$ of precursors are corresponding to the epoxy groups, which disappeared after the amination reaction. The absorption band at $1481 \mathrm{~cm}^{-1}$ is attributed to the $\mathrm{C}-\mathrm{N}$ stretching of quaternary ammonium groups. The broad absorption band ranging from 3200 to $3500 \mathrm{~cm}^{-1}$ originates from $\mathrm{O}-\mathrm{H}$ deformation vibration of hydroxyl groups, proving the success of amination. As shown in Fig. 2b, the saturation magnetizations of resins are in the order of MAER-3 < MAER-2 < MAER-1, and consistent with the increased mass of newly formed functional groups. Furthermore, the curves do not pass through the origin of coordinate, suggesting that the MAERs can behave as a permanent magnet in the absence of an external magnetic field. As a result, the magnetic microbeads could easily agglomerate with others and form flocks without the use of a magnet, which would result in the rapid settling in water and greatly improve the processing wastewater volume, and make it more amenable to automation.

Adsorption kinetics. Adsorption kinetics study was conducted to evaluate the HA adsorption performance onto MAERs. To elucidate the adsorption behaviors of three resins, the pseudo-first order, pseudo-second order and Weber-Morris intra-particle diffusion models were applied and expressed in Text S3.

As shown in Fig. 3a, the adsorption amounts of HA for all resins increased quickly at the initial stage and then slowed down until equilibrium. The fast adsorption at the initial time was due to the concentration gradient between the HA and amounts of active sites at the beginning of adsorption process. It can be seen in Fig. S2 that a negligible uptake of $\mathrm{HA}$ by three precursor resins and $\gamma-\mathrm{Fe}_{2} \mathrm{O}_{3}$ was observed, demonstrating that the direct adsorption of $\mathrm{HA}$ by polymer matrix or $\gamma-\mathrm{Fe}_{2} \mathrm{O}_{3}$ was excluded. As depicted in Fig. 3b, the adsorption of HA onto MAERs can be well fitted by intra-particle diffusion model $\left(R^{2}>0.996\right)$. The HA adsorption consists of three steps: the movement of adsorbates through the diffusion boundary layer, intra particle diffusion and attainment of equilibrium ${ }^{25}$. The first portions of straight lines do not pass through the origin, indicating that intra-particle diffusion is not the only limiting step, and other steps also influence the rate of mass transfer according to the 

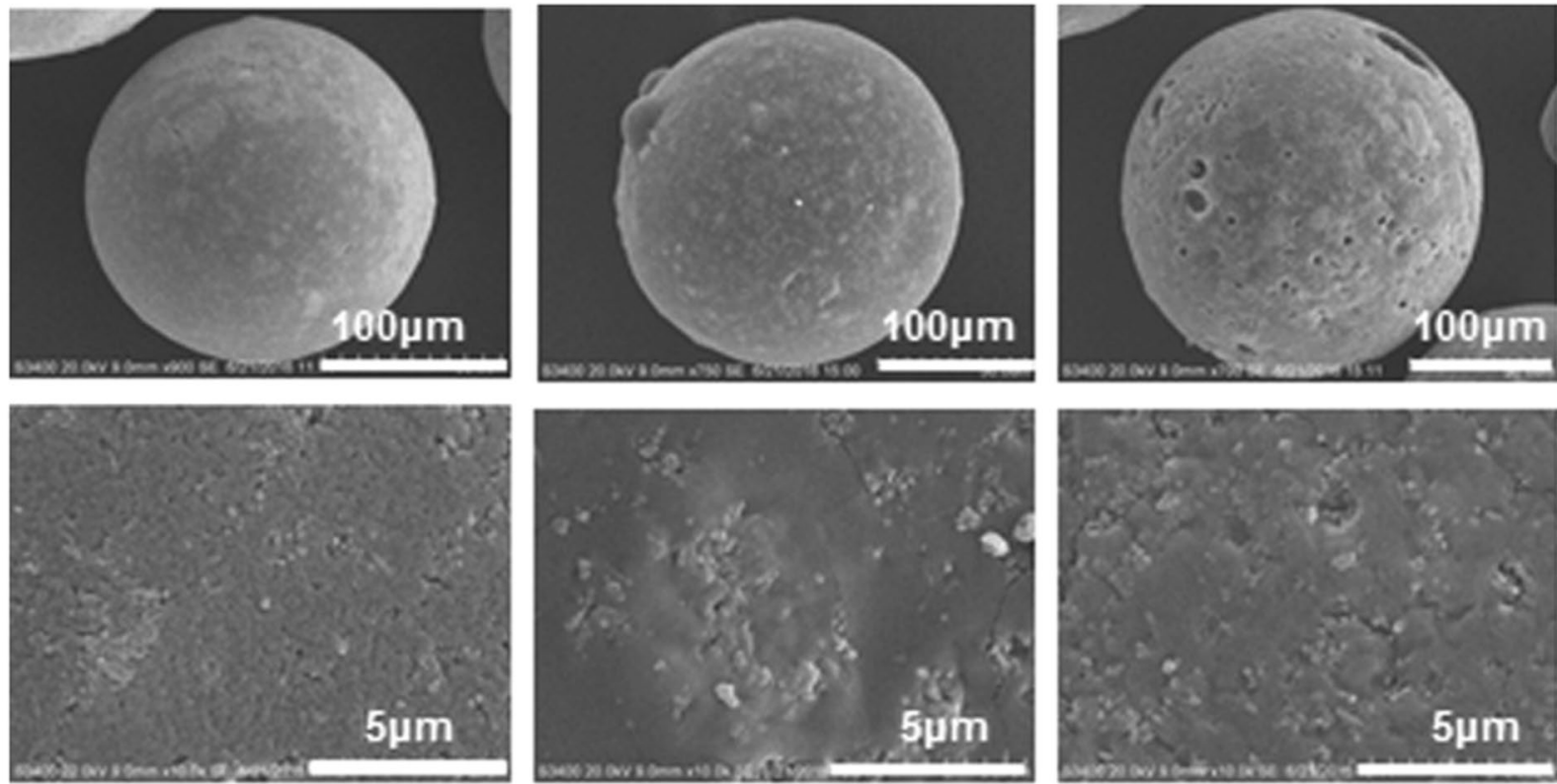

Figure 1. SEM micrographs of (a) MAER-1, (b) MAER-2, and (c) MAER-3.
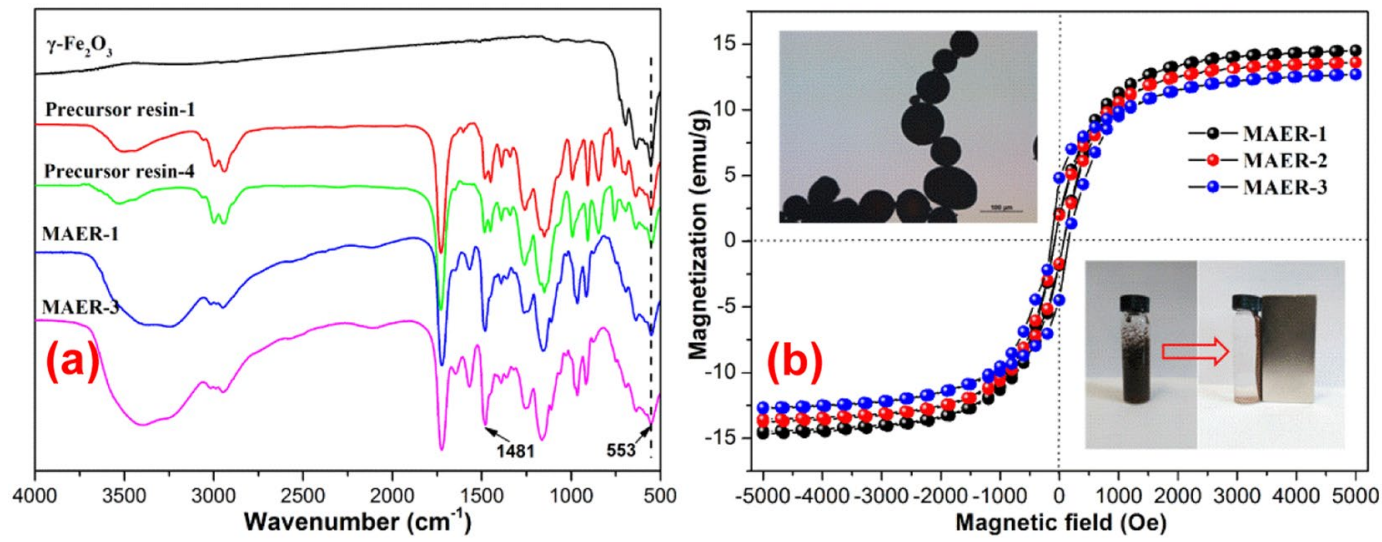

Figure 2. The characterization of MAERs: (a) FTIR spectra, and (b) magnetic hysteresis loops.
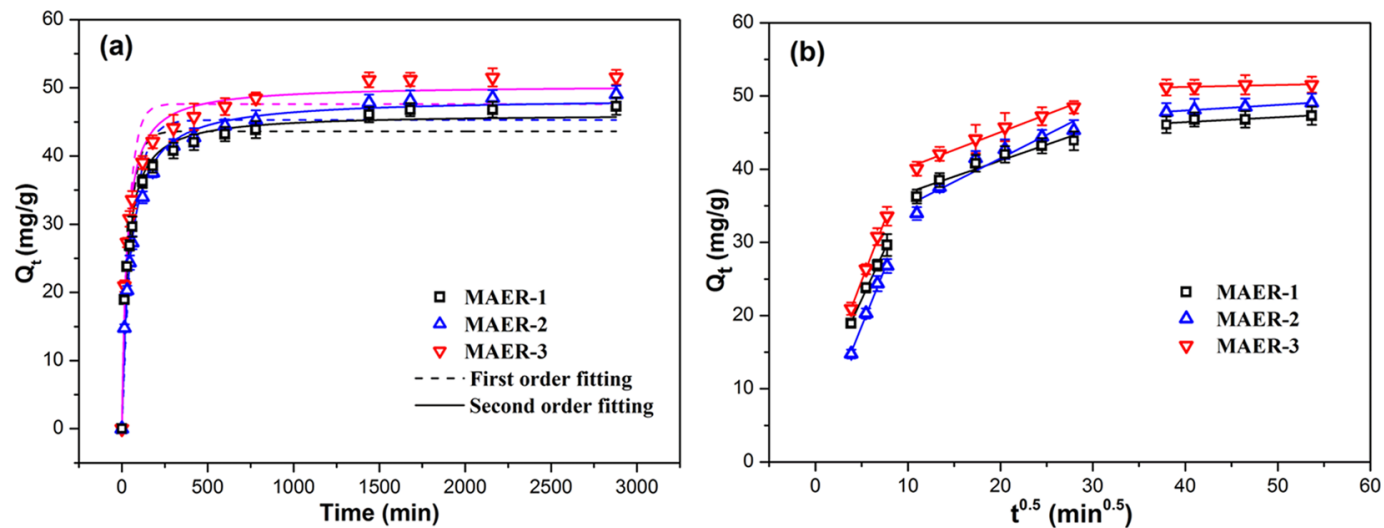

Figure 3. The plots of HA adsorption for (a) pseudo first-order and pseudo second-order kinetics model, and (b) intra-particle diffusion model (1.0 g resin/L, $100 \mathrm{mg} / \mathrm{L}$ of HA solution, $293 \mathrm{~K}$ ). 


\begin{tabular}{|c|c|c|c|c|c|c|c|c|c|c|}
\hline \multirow[b]{2}{*}{ Resin } & \multicolumn{3}{|c|}{ Pseudo-first-order model } & \multicolumn{4}{|c|}{ Pseudo-second-order model } & \multicolumn{3}{|c|}{ Intra-particle diffusion model } \\
\hline & $k_{1} / 10^{-2}\left(\min ^{-1}\right)$ & $q_{e}(\mathrm{mg} / \mathrm{g})$ & $R^{2}$ & $k_{2} / 10^{-4}(\mathrm{~g} / \mathrm{mg} \mathrm{min})$ & $h(\mathrm{mg} / \mathrm{g} \min )$ & $q_{e}(\mathrm{mg} / \mathrm{g})$ & $R^{2}$ & $K_{1 d}\left(\mathrm{mg}(\mathrm{g} \mathrm{min})^{0.5}\right)$ & $I(\mathrm{mg} / \mathrm{g})$ & $R^{2}$ \\
\hline MAER-1 & 2.247 & 43.63 & 0.9378 & 7.304 & 1.558 & 46.18 & 0.9883 & 2.747 & 8.477 & 0.9971 \\
\hline MAER-2 & 1.572 & 45.28 & 0.9492 & 4.582 & 1.078 & 48.51 & 0.9937 & 3.147 & 2.816 & 0.9914 \\
\hline MAER-3 & 2.429 & 47.63 & 0.9302 & 7.197 & 1.828 & 50.40 & 0.9863 & 3.313 & 8.191 & 0.9965 \\
\hline
\end{tabular}

Table 2. Kinetic parameters of three kinetic models at $293 \mathrm{~K}$.

Weber-Morris theory ${ }^{14,26}$. Obviously, the MAER-3 had the fastest adsorption kinetics, which was in accord with the fact that HA adsorption differs among various surfaces, and hydrophilic surface is much superior to hydrophobic surface if electrostatic attraction mainly acts on adsorption ${ }^{27}$.

The kinetic parameters are listed in Table 2. It is evident that the adsorption process under this condition is more suitable described by the pseudo-second-order kinetic model $\left(R^{2}>0.986\right)$, which is in accordance with their chemisorption process. The kinetic constant $k_{1}$ and initial adsorption rate $h$ follow the order: MAER-3 > MAER-1 > MAER-2, indicating the resin with higher hydrophilicity and larger pore size has faster kinetics for HA adsorption. Especially, the supermacroporous structure of the surface of MAER-3 lead to the largest diffusion rate constant of the three resins and greatly facilitate the diffusion and adsorption of high-molecular-weight HA.

On the other hand, it was worth mentioning that a direct comparison of HA adsorption capacity between the examined resins with those obtained in the literature is difficult due to the varying experimental conditions. In this study, the adsorption of HA by using other adsorbents were also performed. The physicochemical property of used adsorbents and adsorption capacity were shown in Table S2 and Figure S3, respectively. As can be seen, the D213 resin with the polyacrylic matrix has the largest adsorption capacity of HA, which was about $25 \%$ larger than that of MAER-3. This phenomenon was mainly due to the fact that the incorporated $\gamma-\mathrm{Fe}_{2} \mathrm{O}_{3}$ in MAER-3 could not participate in the HA adsorption. However, other resins with the hydrophobic polystyrene matrix and activated carbon had much lower HA adsorption capacity, indicating that these commercially available adsorbents were not suitable for HA removal.

Adsorption isotherms. Adsorption isotherm describes the equalibrium between adsorbent in the liquid and adsorbed on the surface of adsorbent at constant temperature. To obtain an enhanced understanding of adsorption mechanism, the isothermal adsorption data are fitted by Langmuir and Freundlich model, respectively. The Langmuir model assumes that adsorption sites are homogeneous and occupied in a one-to-one manner, while Freundlich model is an empirical model based on the assumption of heterogeneous adsorption ${ }^{13,28}$. They are presented as follows:

The Langmuir isotherm: $Q_{e}=Q_{m} K_{L} C_{e} /\left(1+K_{L} C_{e}\right)$

The Freundlich isotherm: $Q e=K_{F} C e^{1 / n}$

where, $Q_{e}\left(\mathrm{mg} \mathrm{g}^{-1}\right)$ and $C_{e}\left(\mathrm{mg} \mathrm{L}^{-1}\right)$ are the adsorption capacity and concentration at the equilibrium state, respectively. $Q_{m}\left(\mathrm{mg} \mathrm{g}^{-1}\right)$ is the theoretical monolayer saturation capacity. $K_{L}$ and $K_{F}$ are the constants of Langmuir and Freundlich model, respectively. $n$ is the Freundlich exponent which serves to describe the adsorption intensity ${ }^{29}$.

It can be observed in Fig. 4 that the equilibrium adsorption amounts of HA increased for all resins with increasing temperature, which is consistent with the characteristic of chemical interaction. As illustrated in Table 3, the adsorption data can be better described by Freundlich model with higher values of correlation constant, suggesting other interactions except ion exchange may exist in HA adsorption. Previous researchers have revealed the cation $-\pi$ bonding and $\pi-\pi$ interaction between organic pollutants and various adsorbent $s^{30,31}$. More recently, the $\pi-\pi$ interaction has been proposed between the adsorbed HA molecules and free HA molecules ${ }^{14,29}$. On the other hand, a high value of $n$ implies strong affinity of HA toward the resin. It is clearly seen that the value of $n$ increased gradually with the increase of temperature. For all resins, the obtained values of $n$ are higher than 1 , and accordingly, the adsorption processes are favorable. More importantly, the Freundlich bonding constant and adsorption capacity are generally increased with the increasing content of DAI, indicating the essential roles of DAI for improving the resin adsorption performance.

To further reflect the feasibility and favorability of HA onto MAERs, the thermodynamic analysis of the adsorption processes was performed. The thermodynamic parameters, including free energy change $(\Delta G)$, enthalpy change $(\Delta H)$ and entropy change $(\Delta S)$, are calculated according to the Eqs (5-7):

$$
\begin{gathered}
\ln (1 / C e)=\ln K_{0}+(-\Delta H / R T) \\
\Delta G=-n R T \\
\Delta G=\Delta H-T \Delta S
\end{gathered}
$$

where $T(\mathrm{~K})$ is the absolute temperature and $n$ is the Freundlich constant. $C_{e}$ is the equilibrium concentration calculated from the well-fitted Freundlich isotherm. $R$ is the gas constant $\left(8.314 \mathrm{~J} \mathrm{~mol}^{-1} \mathrm{~K}^{-1}\right)$. 

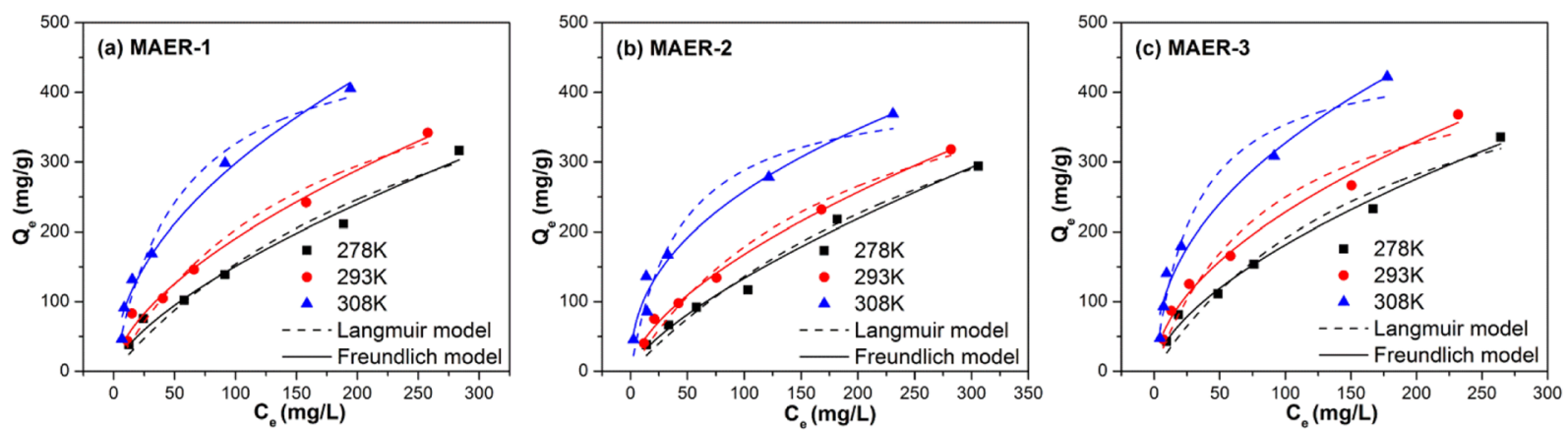

Figure 4. Isotherms of HA adsorption by MAERs at 278, 293 and $308 \mathrm{~K}$.

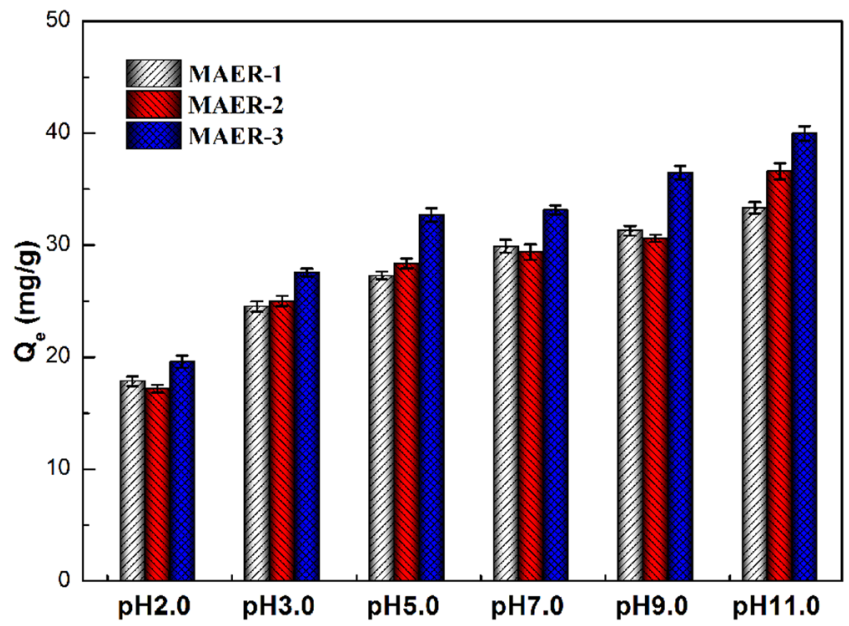

Figure 5. The adsorption amounts of HA onto MAERs at different $\mathrm{pH}$ values $(1.0 \mathrm{~g}$ resin/L, $50 \mathrm{mg} / \mathrm{L}$ of $\mathrm{HA}$ solution, $293 \mathrm{~K})$.

\begin{tabular}{|l|l|l|l|l|l|l|l|}
\hline \multirow{4}{*}{ Adsorbent } & \multicolumn{3}{|l}{ Langmuir model } & \multicolumn{3}{l|}{ Freundlich model } \\
\cline { 2 - 8 } & Temperature $(\mathbf{K})$ & $\left.\boldsymbol{K}_{\mathbf{L}} / \mathbf{1 0}^{-\mathbf{2}} \mathbf{(} / \mathbf{m g}\right)$ & $\mathbf{Q}_{\boldsymbol{m}}(\mathbf{m g} / \mathbf{g})$ & $\boldsymbol{R}^{\mathbf{2}}$ & $\boldsymbol{K}_{\boldsymbol{F}}(\mathbf{L} / \mathbf{g})$ & $\boldsymbol{n}$ & $\boldsymbol{R}^{\mathbf{2}}$ \\
\hline \multirow{3}{*}{ MAER-1 } & 278 & 0.331 & 502.60 & 0.9493 & 6.886 & 1.492 & 0.9790 \\
\cline { 2 - 8 } & 293 & 0.610 & 536.18 & 0.9550 & 12.036 & 1.668 & 0.9861 \\
\cline { 2 - 8 } & 308 & 1.853 & 618.72 & 0.9761 & 30.586 & 2.022 & 0.9799 \\
\hline \multirow{3}{*}{ MAER-2 } & 278 & 0.254 & 413.80 & 0.9738 & 5.017 & 1.403 & 0.9834 \\
\cline { 2 - 8 } & 293 & 0.522 & 519.97 & 0.9766 & 9.797 & 1.622 & 0.9955 \\
\cline { 2 - 8 } & 308 & 2.297 & 670.24 & 0.9428 & 35.757 & 2.330 & 0.9741 \\
\hline \multirow{3}{*}{ MAER-3 } & 278 & 0.545 & 461.80 & 0.9529 & 11.194 & 1.654 & 0.9875 \\
\cline { 2 - 8 } & 293 & 1.113 & 474.40 & 0.9451 & 19.770 & 1.882 & 0.9869 \\
\cline { 2 - 8 } & 308 & 3.278 & 541.01 & 0.9577 & 42.365 & 2.252 & 0.9721 \\
\hline
\end{tabular}

Table 3. Adsorption parameters of Langmuir and Freundlich isotherm models.

As can be observed in Table $\mathrm{S} 3$, the $\Delta G$ values are all negative at three temperatures and increased with the increasing temperatures, revealing that HA adsorption by MAERs is spontaneous and thermodynamically favorable. The positive values of $\Delta H$ prove the adsorption processes are endothermic and mainly dominated by chemical adsorption $\left(40-140 \mathrm{~kJ} \mathrm{~mol}^{-1}\right)$. However, the relatively lower values of $\Delta H$ than the usual chemical adsorption imply the existence of other physical forces. Furthermore, the positive values of $\Delta S$ indicate that the HA adsorption is dominated by entropic change. These thermodynamic parameters of HA adsorption are consistent with other studies ${ }^{10,14,28}$.

Effect of $\mathrm{pH}$. The solution $\mathrm{pH}$ is a key factor which can significantly affect the ionization degree of HA molecules $^{32}$. In this research, the influences of solution $\mathrm{pH}$ on $\mathrm{HA}$ adsorption were investigated over the $\mathrm{pH}$ range of 3.0-11.0. Figure 5 showed that the adsorption behaviors were all $\mathrm{pH}$-dependent. Generally, with the increase 


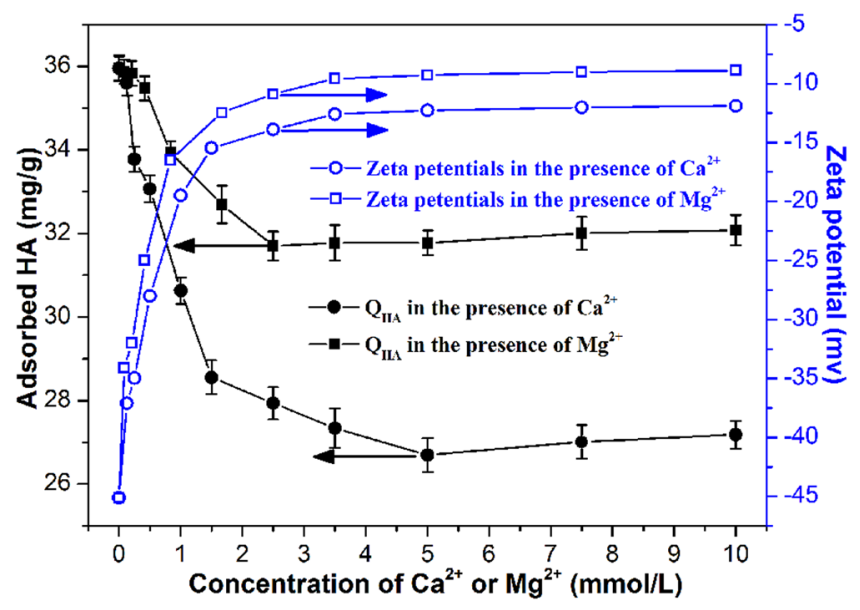

Figure 6. The $\mathrm{HA}$ adsorption capacities and zeta potentials as a function of $\mathrm{Ca}^{2+}$ and $\mathrm{Mg}^{2+}$ concentration $(1.0 \mathrm{~g}$ resin/L, $50 \mathrm{mg} / \mathrm{L}$ of HA solution, $293 \mathrm{~K}$ ).

of $\mathrm{pH}$ value, the HA adsorption amounts increased as well. At most $\mathrm{pHs}$, the adsorbed HA was in the order of MAER- $1 \approx$ MAER-2 < MAER-3. At pH 11.0, the removal efficiency of HA by MAER-3 was nearly $80 \%$.

The adsorption behaviors could be explained by the variation of zeta potentials. Due to the quaternary ammonium groups of the resin matrix, the MAERs were positively charged and maintained stable at both acidic and basic conditions ${ }^{33}$. On the other hand, the zeta potentials of HA molecules varied considerably in the tested $\mathrm{pH}$ range due to their dissociation of carboxyl groups and phenolic hydroxyl groups (Fig. S4a). Interestingly, the surface charge became less negative at strongly basic conditions. This may be interpreted by the variation of molecular shape and size of HA at different $\mathrm{pH}$ values. As shown in Fig. S4b, the sizes of HA molecules at weakly acidic conditions were greatly larger than that at basic conditions, while the size of HA molecules at $\mathrm{pH} 9.5$ was in a wide distribution. However, the size distributions of HA molecules at strongly acidic condition were not given for their precipitation and much higher deviation. Under acidic conditions (like $\mathrm{pH}$ 2.0), HA macromolecules were near neutral, thus the adsorption was more favored by other driving forces, such as cation- $\pi$ bonding between quaternary ammonium groups of MAERs and $\pi$-electron-rich HA aromatic structures (act as $\pi$-donors), and $\pi-\pi$ interaction between free $\mathrm{HA}$ and absorbed $\mathrm{HA}^{14,34}$. Furthermore, the electrostatic attraction between the newly formed positively charged oxonium groups (derived from the oxygen atom of $\mathrm{C}-\mathrm{O}-\mathrm{C}$ in the resin matrix) and HA molecules should also be mentioned ${ }^{35,36}$. Taken together, the increasing amounts of adsorbed HA were consistent with the disaggregation of coalesced HA molecules and formation of chain-shaped structure, which resulted in a more effective diffusion of HA molecules into the interior part of resin.

Effects of cations. As alkaline-earth metal ions always exist in various water systems, it is of vital importance to investigate the impacts of co-existing cations on HA adsorption ${ }^{28,37}$. In our preliminary experiments, similar adsorption behaviors were observed for all resins. Therefore, batch experiments were performed by using MAER-3 only, and the results were depicted in Fig. 6. As can be seen, the adsorption amounts of HA by MAER-3 decreased substantially with the concentrations of $\mathrm{Ca}^{2+}$ and $\mathrm{Mg}^{2+}$ increasing from 0 to $10.0 \mathrm{mmol} \mathrm{L}{ }^{-1}$, which was $24.39 \%$ decrease for $\mathrm{Ca}^{2+}$ and $10.79 \%$ decrease for $\mathrm{Mg}^{2+}$, respectively. These results could be explained by the obvious decline in zeta potentials of HA solution. Although chelating interactions between alkaline-earth metal ions and HA molecules are weak, they can still form complexes and neutralize the negative charge of HA molecules, thus decrease the adsorptive force ${ }^{28,38}$. In addition, $\mathrm{Ca}^{2+}$ exerted a more pronounced influence on $\mathrm{HA}$ removal than $\mathrm{Mg}^{2+}$, which was mainly due to the lower affinity between $\mathrm{Mg}^{2+}$ and carboxylic groups of $\mathrm{HA}^{29}$. Interestingly, it was found that the HA adsorption capacity had a limited rise with the concentrations of cations increasing from 5 to $10 \mathrm{mmol} \mathrm{L}^{-1}$. It is reasonable to assume that the cations could also decrease the electrostatic repulsion between free and adsorbed HA macromolecules, and create new sites for adsorption. Besides, the coiling of cation-HA complexes can reduce the molecular size and solubility of HA (known as the salting-out effect), leading to an enhancement in HA adsorption capacities.

Desorption and reusability. With the aim of industrial-scale applications, the reusability of MAERs is of great importance ${ }^{20,39}$. Due to the large molecular size and high hydrophobicity of HA, it could seriously hamper the adsorption and desorption behaviors by pore blocking or site shielding ${ }^{40}$. Brine is typically used for anion exchange resin regeneration as it can replace the adsorbed anionic adsorbate ${ }^{41,42}$. However, the hydrophobic interaction between adsorbents and adsorbate may be enhanced with the increasing $\mathrm{NaCl}$ in solution, which results in the fouling of resins.

In this study, desorption experiments were carried out by using $10 \% \mathrm{NaCl}$ solution or a mixture of $10 \%$ $\mathrm{NaCl}+1 \% \mathrm{NaOH}$ solution as the desorption agent, respectively. As shown in Fig. S5, the desorption efficiencies $(D E s)$ by $\mathrm{NaCl} / \mathrm{NaOH}$ mixture were much higher than that of $\mathrm{NaCl}$ solution only, which was reasonable for the reduced hydrophobic interaction and dissociation of $\mathrm{HA}$ molecules in the presence of $\mathrm{NaOH}$. Furthermore, the MAER-3 exhibited better desorption performance than other resins by using pure $\mathrm{NaCl}$ solution, which may be attributed to its obviously enhanced hydrophilicity and supermacroporous structure on the surface. This being 


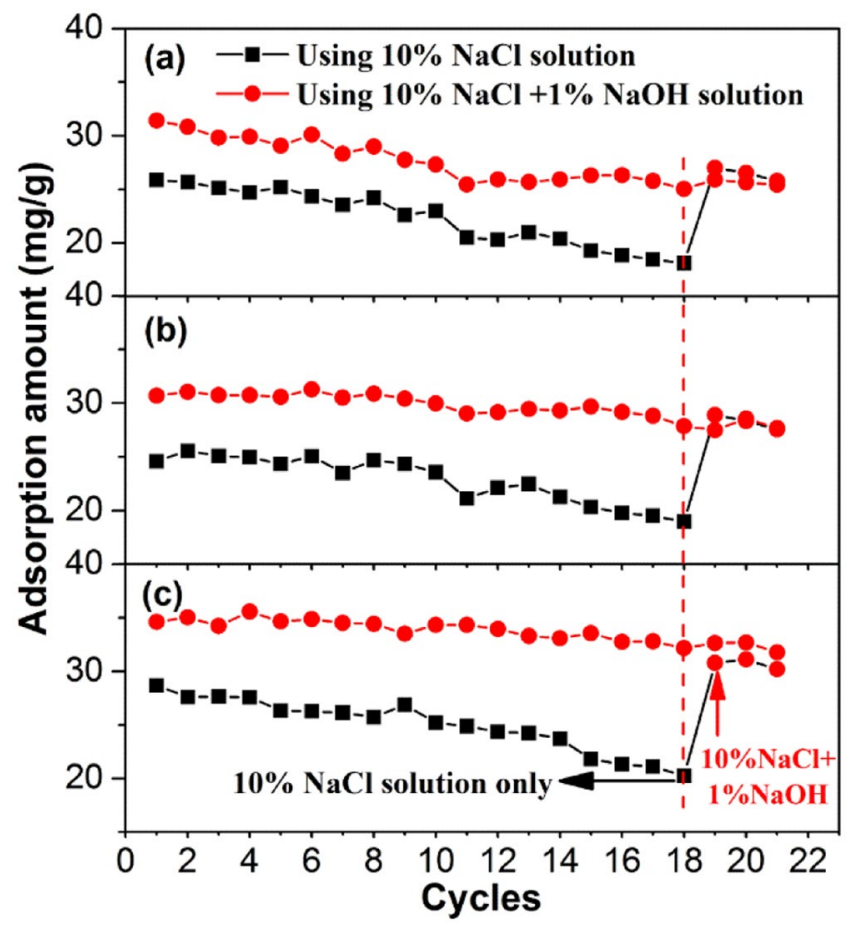

Figure 7. The adsorption amounts of HA during twenty-one adsorption cycles by (a) MAER-1, (b) MAER-2, and (c) MAER-3 (1.0 g resin/L, $50 \mathrm{mg} / \mathrm{L}$ of HA solution, $293 \mathrm{~K}$ ).

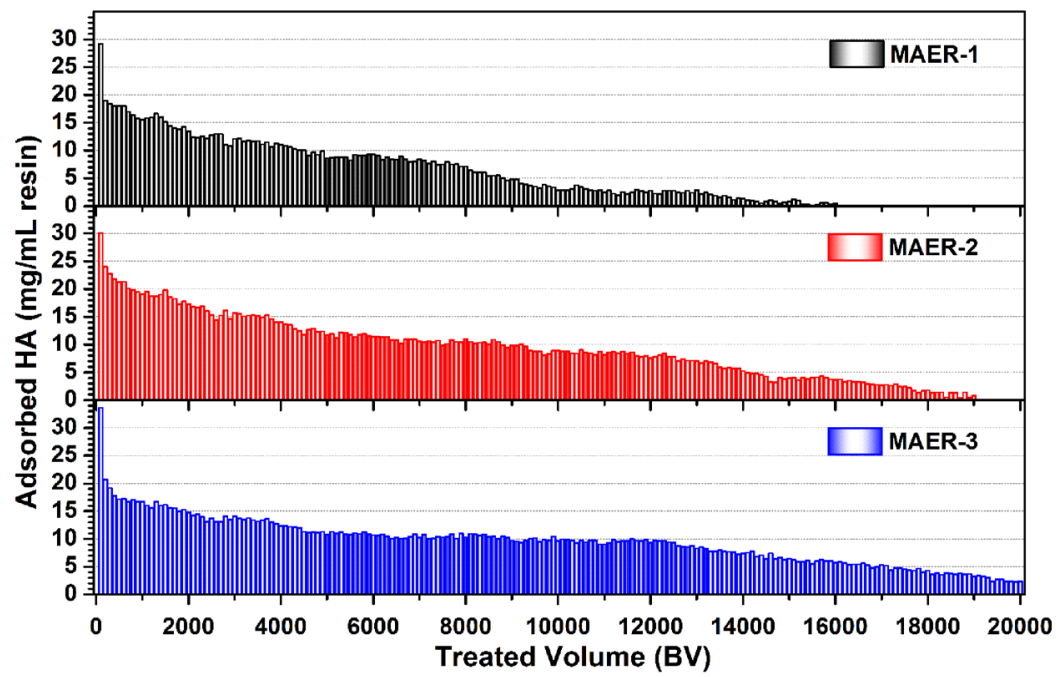

Figure 8. The HA adsorption performances by using MAERs in sequencing batch mode $(1.0 \mathrm{~mL}$ resin, $50 \mathrm{mg} / \mathrm{L}$ of HA solution, $293 \mathrm{~K}$ ).

the case, the improved anti-fouling performance of MAER-3 was directly on account of its higher DAI content in composition.

The repeated adsorption-desorption processes were performed for 21 times to verify the reusability of MAERs. As shown in Fig. 7, the decline trends of HA adsorption for all resins were observed. After 18 adsorption-desorption cycles, the total decreases in $\mathrm{HA}$ adsorption capacity regenerated by $\mathrm{NaCl} / \mathrm{NaOH}$ mixture were $20.34 \%, 9.26 \%$ and $7.09 \%$ for the recycling MAER-1, MAER-2, and MAER-3, respecitvely, while that by pure $\mathrm{NaCl}$ solution were $30.03 \%, 24.36 \%$, and $26.83 \%$, respectively. Moreover, the residual HA on resins due to the insufficient desorption by $\mathrm{NaCl}$ solution could be again desorbed by a mixture of $\mathrm{NaCl} / \mathrm{NaOH}$ solution, as verified by the last three cycles. Also, the resins with larger DAI content, which meant higher hydrophilicity, exhibited better reusability potential, especially for MAER-3. Furthermore, as depicted in Fig. 8, an efficient adsorption of HA was observed for more than 15000 bed volume (BV) HA solution. The gradual loss of removal efficiency was attributed to the progressive loss of resin capacity during multiple cycles of HA removal. The saturated capacities 

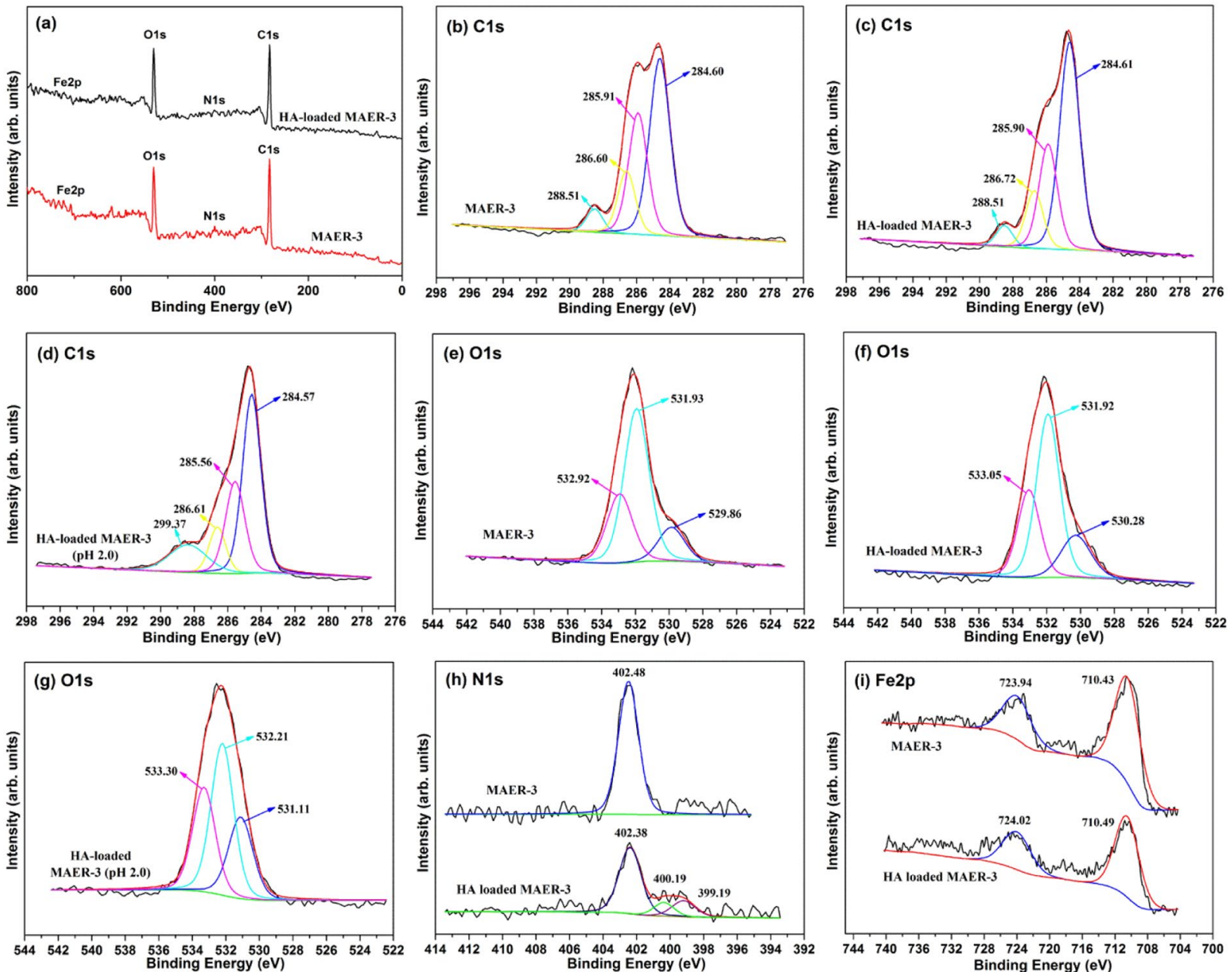

Figure 9. XPS spectra of (a) wide scan of virgin and HA-loaded MAER-3, (b-d) C1s spectra of virgin, HAloaded and acidic HA-loaded MAER-3, (e-g) O1s spectra of virgin, HA-loaded and acidic HA-loaded MAER-3, (h) N1s spectra of virgin and HA-loaded MAER-3, and (i) Fe2p spectra of virgin and HA-loaded MAER-3.

of MAER-1, MAER-2 and MAER-3 for HA adsorption were 1118.9, 1714.6 and $1896.7 \mathrm{mg} / \mathrm{mL}$ resin, respectively, demonstrating their huge potential for HA adsorption. Based on the advantages of superior reusability, high adsorption capacity and convenient separability, the MAER-3 can be considered as an environmentally friendly and reusable adsorbent for NOM removal.

Mechanism. SEM morphologies of single-bead and resin surface before and after adsorption of HA were observed in Fig. S6. No obvious differences were found for the overall morphologies of three resins. However, it was evident that adsorption of HA caused obviously morphological alteration on the exterior of resin surface. The thicker layer of surface coverage and masking of adsorptive sites by HA molecules suggested that the monolayer adsorption by electrostatic attraction may turn into multilayer adsorption by physical forces, which was formerly indicated by the Freundlich isotherm fitting.

The FTIR results also shed light on the nature of adsorptive interactions between HA and MAERs. As shown in Fig. S7a, slight changes were observed in the FTIR spectra of the two resins. However, the peaks at $1567.9 \mathrm{~cm}^{-1}$ for MAER-1 and $1571.7 \mathrm{~cm}^{-1}$ for MAER-3 were corresponding to the $\mathrm{C}=\mathrm{O}$ of the resin matrix, which shifted to $1564.0 \mathrm{~cm}^{-1}$ and $1565.9 \mathrm{~cm}^{-1}$, respectively, indicating that the carbonyl groups may form hydrogen bonding with the un-ionized HA. Besides, the FTIR results at acidic conditions were shown in Fig. S7b. The peaks of C-O-C groups of the resin matrix were shifted from $1159 \mathrm{~cm}^{-1}$ to about $1147 \mathrm{~cm}^{-1}$, confirming the interactions between $\mathrm{HA}$ molecules and the oxygen atoms of $\mathrm{C}-\mathrm{O}-\mathrm{C}$, and possible formation of oxonium groups (Fig. S8). The effects of oxygen atom of C-O-C for adsorption have been discussed in previous literatures ${ }^{35,43-45}$. It is said that both oxygen atoms of carbonyl and ester groups have a lone pair of electrons that can bind a proton ion through an electron pair sharing and form a complex. According to Yang et al. ${ }^{35}$, the existence of oxonium groups was confirmed during the adsorption of aromatic sulfonate by acrylic ester resin in an acidified solution.

XPS characterization was conducted to elucidate the adsorption mechanisms. The high-resolution C1s, O1s, $\mathrm{N} 1 \mathrm{~s}, \mathrm{Fe} 2 \mathrm{p}$ spectra as well as the wide scans of virgin and HA-saturated resin samples were shown in Fig. 9. The deconvolution of $\mathrm{C} 1 \mathrm{~s}$ spectra for MAER-3 was resolved into four peaks centered at 284.60, 285.91, 286.60, and $288.51 \mathrm{eV}$, which was attributed to the $\mathrm{C}-\mathrm{C} / \mathrm{C}-\mathrm{H}, \mathrm{C}-\mathrm{O}-\mathrm{C} / \mathrm{C}-\mathrm{OH}, \mathrm{C}-\mathrm{N}^{+}$, and $\mathrm{O}-\mathrm{C}=\mathrm{O}$ groups, respectively ${ }^{35}$. 
After HA uptake, the shifts of four peaks in C1s spectra were negligible. However, for the C1s spectra of HA-loaded MAER-3 at $\mathrm{pH} 2.0$, the contents of $\mathrm{O}-\mathrm{C}=\mathrm{O}$ increased greatly, while the peak corresponding to carbon atoms of $-\mathrm{CH} 2-\mathrm{O}-$ at $285.91 \mathrm{eV}$ shifted to $285.56 \mathrm{eV}$, indicating that this group played important roles in the HA adsorption. These results also suggested the possible formation of oxonium groups at the acidic condition.

The O1s spectra of MAER-3 were divided into three sub-peaks at 529.86, 531.93 and $532.92 \mathrm{eV}$, which were assigned to the $\mathrm{C}=\mathrm{O}, \mathrm{O}-\mathrm{H}$, and $\mathrm{C}-\mathrm{O}$, respectively ${ }^{46}$. After $\mathrm{HA}$ loading, the peaks of $\mathrm{C}=\mathrm{O}$ and $\mathrm{C}-\mathrm{O}$ shifted to 530.28 and $533.05 \mathrm{eV}$, while no obvious shift was observed for $\mathrm{O}-\mathrm{H}$ groups. Additionally, the O1s sub-peaks for HA-loaded MAER-3 at pH 2.0 shifted greatly, along with the intensity of $\mathrm{C}=\mathrm{O}$ and $\mathrm{C}-\mathrm{O}$ peaks increased obviously. The N1s spectra of MAER-3 had a single peak at $402.48 \mathrm{eV}$ for the quaternary ammonium-type $\mathrm{N}^{29,32}$. After HA adsorption, this peak shifted slightly to $402.38 \mathrm{eV}$, while two other peaks at lower binding energies appeared, which was definitely derived from the $\mathrm{N}$-containing groups of $\mathrm{HA}$ molecules ( $\mathrm{N}$ content of $3.73 \%$ for HA) like $-\mathrm{CN},-\mathrm{N}=,-\mathrm{NH}-\mathrm{I}-\mathrm{HH}_{2},-\mathrm{OCONH}-$, and $-\mathrm{CONH}_{2}{ }^{40}$. In the Fe2p spectra, the broad peaks of Fe2p3/2 and $\mathrm{Fe} 2 \mathrm{p} 1 / 2$ spectra were positioned at 710.43 and $723.94 \mathrm{eV}$, respectively. After HA adsorption, no obvious changes were found for Fe2p spectra, which also confirmed the non-interaction between HA molecules and $\gamma-\mathrm{Fe}_{2} \mathrm{O}_{3}$.

\section{Conclusions}

In this study, a series of novel permanent-magnetic anion exchange resins called MAERs were developed and applied for HA removal. The MAERs were about $50-150 \mu \mathrm{m}$ in size with uniform grain diameter and exhibited high rates of settlement in aqueous solution due to their superior magnetic characteristics. The use of DAI as the crosslinker can significantly improve the hydrophilicity, strength and adsorption capacity of resins, thereby suggesting a feasible method to enhance the adsorptive and anti-fouling performance of resins. The kinetic studies showed that the HA adsorption can be well fitted by pseudo-second-order and intra-particle diffusion model, and the diffusion constants increased with the increasing DAI content. Furthermore, the Freundlich isotherm model was more suitable for explaining the HA adsorption onto MAERs. The thermodynamic analysis of the adsorption process showed that the adsorption of HA by MAERs was an endothermic spontaneous reaction. The HA uptake depended highly on the solution $\mathrm{pH}$ and increased gradually as $\mathrm{pH}$ increased from 3.0 to 11.0. On the other hand, with the increase in the concentrations of co-existing cations $\left(\mathrm{Ca}^{2+}\right.$ or $\left.\mathrm{Mg}^{2+}\right)$, the adsorption capacities decreased drastically at initial and increased a little at high cation concentrations. Ion exchange was proposed as the main adsorption mechanism, while hydrogen bonding, $\pi-\pi$ interaction, cation- $\pi$ bonding and formation of oxonium groups also played important roles in the HA adsorption. The HA-saturated MAERs can be efficiently regenerated by a mixture of $\mathrm{NaCl} / \mathrm{NaOH}$ solution $(10 \% / 1 \%)$. During twenty-one adsorption-desorption cycles, the MAER-3 could be reused without an obvious decline in adsorption capacity, indicating a superior anti-fouling performance for HA removal. Taken together, the high capacity, fast kinetics, excellent reusability and convenient separability of MAER-3 made it a good candidate for NOM removal in water treatment.

\section{References}

1. Liu, C. \& Bai, R. Recent advances in chitosan and its derivatives as adsorbents for removal of pollutants from water and wastewater. Current Opinion in Chemical Engineering 4, 62-70 (2014).

2. Boyer, T. H. \& Singer, P. C. Bench-scale testing of a magnetic ion exchange resin for removal of disinfection by-product precursors. Water Res. 39, 1265-1276 (2005).

3. Ma, L. \& Zhang, W.-x. Enhanced biological treatment of industrial wastewater with bimetallic zero-valent iron. Environ. Sci. Technol. 42, 5384-5389 (2008).

4. Gharabaghi, M., Irannajad, M. \& Azadmehr, A. R. Selective sulphide precipitation of heavy metals from acidic polymetallic aqueous solution by thioacetamide. Ind. Eng. Chem. Res. 51, 954-963 (2012).

5. Pantke, C. et al. Green rust formation during Fe (II) oxidation by the nitrate-reducing Acidovorax sp. strain BoFeN1. Environ. Sci. Technol. 46, 1439-1446 (2012).

6. Li, Q., Qi, Y. \& Gao, C. Chemical regeneration of spent powdered activated carbon used in decolorization of sodium salicylate for the pharmaceutical industry. J. Clean. Prod. 86, 424-431 (2015).

7. Zhu, X., Loo, H.-E. \& Bai, R. A novel membrane showing both hydrophilic and oleophobic surface properties and its non-fouling performances for potential water treatment applications. J.Membrane Sci. 436, 47-56 (2013).

8. Li, Q. et al. Competition and enhancement effect in coremoval of atenolol and copper by an easily regenerative magnetic cation exchange resin. Chemosphere 179, 1-9 (2017).

9. Cheng, C., Wang, J., Yang, X., Li, A. \& Philippe, C. Adsorption of Ni(II) and Cd(II) from water by novel chelating sponge and the effect of alkali-earth metal ions on the adsorption. J. Hazard. Mater. 264, 332-341 (2014).

10. Wang, W. et al. Effect of humic acid on ciprofloxacin removal by magnetic multifunctional resins. Sci. Rep. 6, 30331 (2016).

11. Ding, L., Deng, H., Wu, C. \& Xu, H. Affecting factors, equilibrium, kinetics and thermodynamics of bromide removal from aqueous solutions by MIEX resin. Chem. Eng. J. 181-182, 360-370 (2012).

12. Indarawis, K. \& Boyer, T. H. Alkaline Earth Metal Cation Exchange: Effect of Mobile Counterion and Dissolved Organic Matter. Environ. Sci. Technol. 46, (2012).

13. Shuang, C. et al. Quaternized magnetic microspheres for the efficient removal of reactive dyes. Water Res. 46, 4417-4426 (2012).

14. Shuang, C. et al. Magnetic polyacrylic anion exchange resin: preparation, characterization and adsorption behavior of humic acid. Ind. Eng. Chem. Res. 51, 4380-4387 (2012).

15. Boyer, T. H. Removal of Dissolved Organic Matter by Magnetic Ion Exchange Resin. Curr. Pollution Rep. 1, 142-154 (2015).

16. Boyer, T. H. \& Singer, P. C. Stoichiometry of Removal of Natural Organic Matter by Ion Exchange. Environ. Sci. Technol. 42, 608-613 (2008).

17. Zagklis, D. P., Vavouraki, A. I., Kornaros, M. E. \& Paraskeva, C. A. Purification of olive mill wastewater phenols through membrane filtration and resin adsorption/desorption. J. Hazard. Mater. 285, 69-76 (2015).

18. Mergen, M. R., Jefferson, B., Parsons, S. A. \& Jarvis, P. Magnetic ion-exchange resin treatment: Impact of water type and resin use. Water Res. 42, 1977-1988 (2008).

19. Ochoa, N. A., Masuelli, M. \& Marchese, J. Development of charged ion exchange resin-polymer ultrafiltration membranes to reduce organic fouling. J. Membrane Sci. 278, 457-463 (2006).

20. Li, H., Li, A., Shuang, C., Zhou, Q. \& Li, W. Fouling of anion exchange resin by fluorescence analysis in advanced treatment of municipal wastewaters. Water Res. 66, 233-241 (2014).

21. Li, K. et al. Control of natural organic matter fouling of ultrafiltration membrane by adsorption pretreatment: Comparison of mesoporous adsorbent resin and powdered activated carbon. J. Membrane Sci. 471, 94-102 (2014). 
22. Fu, P. L. K. \& Symons, J. M. Removing Aquatic Organic Substances by Anion Exchange Resins. Journal 82, 70-77 (1990).

23. Croué, J. P., Violleau, D., Bodaire, C. \& Legube, B. Removal of hydrophobic and hydrophilic constituents by anion exchange resin. Water Sci. Technol. 40, 207-214 (1999).

24. Wang, D., Guan, K., Bai, Z. \& Liu, F. Facile preparation of acid-resistant magnetite particles for removal of Sb(III) from strong acidic solution. Sci. Technol. Adv. Mat. 17, 80-88 (2016).

25. Lorenc-Grabowska, E. \& Gryglewicz, G. Adsorption of lignite-derived humic acids on coal-based mesoporous activated carbons. J. Colloid Interf. Sci. 284, 416-423 (2005).

26. Morris, J. C. \& Jr, W. J. W. Removal of Biologically-Resistant Pollutants from Waste Waters Byadsorption. Adv. Wat. Pol. Res. 269, 231-266 (1964)

27. And, M. J. A. \& Koopal, L. K. Kinetics of Humic Acid Adsorption at Solid-Water Interfaces. Environ. Sci. Technol. 33, 2739-2744 (1999).

28. Wang, J., Zhou, Y., Li, A. \& Xu, L. Adsorption of humic acid by bi-functional resin JN-10 and the effect of alkali-earth metal ions on the adsorption. J. Hazard. Mater. 176, 1018-1026 (2010).

29. Fu, L. et al. High-efficient technique to simultaneous removal of $\mathrm{Cu}(\mathrm{II}), \mathrm{Ni}(\mathrm{II})$ and tannic acid with magnetic resins: Complex mechanism behind integrative application. Chem. Eng. J. 263, 83-91 (2015).

30. Chen, L. et al. Citric Acid Enhanced Copper Removal by a Novel Multi-amines Decorated Resin. Sci. Rep. 5, 9944 (2015).

31. Zhang, Z.-y. \& Xu, X.-c. Wrapping carbon nanotubes with poly (sodium 4-styrenesulfonate) for enhanced adsorption of methylene blue and its mechanism. Chem. Eng. J. 256, 85-92 (2014).

32. Deng, S. \& Bai, R. B. Aminated Polyacrylonitrile Fibers for Humic Acid Adsorption: Behaviors and Mechanisms. Environ. Sci. Technol. 37, 5799-5805 (2003).

33. Wang, J. et al. Effect of pore structure on adsorption behavior of ibuprofen by magnetic anion exchange resins. Micropor. Mesopor.s Mat. 210, 94-100 (2015).

34. Wu, D. et al. Coadsorption of $\mathrm{Cu}$ and sulfamethoxazole on hydroxylized and graphitized carbon nanotubes. Sci. Total Environ. 427, 247-252 (2012).

35. Yang, W., Li, A., Zhang, Q., Fei, Z. \& Liu, F. Adsorption of 5-sodiosulfoisophthalic acids from aqueous solutions onto acrylic ester polymer YWB-7 resin. Sep. Purif. Technol. 46, 161-167 (2005).

36. Fan, J., Li, A., Yang, W., Yang, L. \& Zhang, Q. Adsorption of water-soluble dye X-BR onto styrene and acrylic ester resins. Sep. Purif. Technol. 51, 338-344 (2006).

37. Luo, Q., Zhao, C., Liu, G. \& Ren, H. A Porous Aromatic Framework Constructed from Benzene Rings Has a High Adsorption Capacity for Perfluorooctane Sulfonate. Sci. Rep. 6, 20311 (2016).

38. Pandey, A. K., Pandey, S. D. \& Misra, V. Stability Constants of Metal-Humic Acid Complexes and Its Role in Environmental Detoxification. Ecotox. Environ. Safe. 47, 195-200 (2000).

39. Deng, S., Yu, Q., Huang, J. \& Yu, G. Removal of perfluorooctane sulfonate from wastewater by anion exchange resins: Effects of resin properties and solution chemistry. Water Res. 44, 5188-5195 (2010).

40. Lian, F. et al. Effect of humic acid (HA) on sulfonamide sorption by biochars. Environ. Pollut. 204, 306-312 (2015).

41. Bergquist, A. M., Choe, J. K., Strathmann, T. J. \& Werth, C. J. Evaluation of a hybrid ion exchange-catalyst treatment technology for nitrate removal from drinking water. Water Res. 96, 177-187 (2016).

42. Zhou, Y. et al. Simultaneous removal of atrazine and copper using polyacrylic acid-functionalized magnetic ordered mesoporous carbon from water: adsorption mechanism. Sci. Rep. 7, 43831 (2017).

43. Yang, W. B., Li, A., Fan, J., Yang, L. \& Zhang, Q. Adsorption of branched alkylbenzene sulfonate onto styrene and acrylic ester resins. Chemosphere 64, 984-990 (2006).

44. Lawrinenko, M. \& Laird, D. A. Anion exchange capacity of biochar. Green Chem. 17, 4628-4636 (2015).

45. Altenbach, B. \& Giger, W. Determination of benzene-and naphthalenesulfonates in wastewater by solid-phase extraction with graphitized carbon black and ion-pair liquid chromatography with UV detection. Anal. Chem. 67, 2325-2333 (1995).

46. Ma, Y. et al. A bifunctional adsorbent with high surface area and cation exchange property for synergistic removal of tetracycline and $\mathrm{Cu}^{2+}$. Chem. Eng. J. 258, 26-33 (2014).

\section{Acknowledgements}

The authors would like to express appreciation for the generous support provided by the National Natural Science Foundation of China (51438008, 51678289, and 51408299), Natural Science Foundation of Jiangsu Province (BK20140608) and Postgraduate Research \& Practice Innovation Program of Jiangsu Province (KYCX17_0032). The authors also thank the generous support from the European Union's Horizon H2020 Research and Innovation program MADFORWATER (No. 688320).

\section{Author Contributions}

Q.L. prepared the magnetic anion-exchange resins MAERs, did most of the experiments and wrote this manuscript. J.W., G.Z. and W.L. participated in the data analysis and discussed the results. M.H. did the additional sequencing jar tests and calculated the thermodynamic parameters. C.S. and A.L. designed the experiments of the research. All authors involved in writing and revising the manuscript.

\section{Additional Information}

Supplementary information accompanies this paper at https://doi.org/10.1038/s41598-017-17360-8.

Competing Interests: The authors declare that they have no competing interests.

Publisher's note: Springer Nature remains neutral with regard to jurisdictional claims in published maps and institutional affiliations.

Open Access This article is licensed under a Creative Commons Attribution 4.0 International License, which permits use, sharing, adaptation, distribution and reproduction in any medium or format, as long as you give appropriate credit to the original author(s) and the source, provide a link to the Creative Commons license, and indicate if changes were made. The images or other third party material in this article are included in the article's Creative Commons license, unless indicated otherwise in a credit line to the material. If material is not included in the article's Creative Commons license and your intended use is not permitted by statutory regulation or exceeds the permitted use, you will need to obtain permission directly from the copyright holder. To view a copy of this license, visit http://creativecommons.org/licenses/by/4.0/.

(C) The Author(s) 2017 